\title{
ChemComm
}

\section{Highly porous conjugated polymers for selective oxidation of organic sulfides under visible light $\uparrow$}

Cite this: Chem. Commun., 2014, 50, 8177

Received 17th April 2014,

Accepted 5th June 2014

DOI: $10.1039 / c 4 c c 02861 a$

www.rsc.org/chemcomm

High surface area porous conjugated polymers were synthesized via the high internal phase emulsion polymerization technique and micropore engineering as efficient heterogeneous photocatalysts for highly selective oxidation of organic sulfides to sulfoxides under visible light.

Conjugated porous polymers, combining the photoactive $\pi$-electron backbone and porous surface properties, have been recently introduced as heterogeneous photocatalysts for the organic synthesis under visible light irradiation. ${ }^{1-5}$ Polymers obtained by high internal phase emulsion polymerization (polyHIPEs), which is a relatively new technique for the preparation of highly porous materials, showed versatile applications such as tissue engineering scaffolds, ${ }^{6}$ enzyme immobilization, ${ }^{7,8}$ gas storage, ${ }^{9}$ and separation media. ${ }^{10}$ Due to the micrometer-sized pore structures, which are highly suitable for mass transfer, polyHIPEs are also used as catalyst supports. ${ }^{11}$ Only a few reports on the synthesis of photocatalysts by HIPE polymerization have been published. ${ }^{12,13}$ Recently, the synthesis of the first example of fully conjugated polyHIPEs was reported; these materials have surface areas of $35-50 \mathrm{~m}^{2} \mathrm{~g}^{-1}$ and could be used as highly efficient and reusable heterogeneous photosensitizers for the singlet oxygen generation under visible light. ${ }^{13}$ Combining the interconnected porosity of polyHIPEs and the conjugated framework throughout the polymer network, conjugated polyHIPEs hold great promise in heterogeneous photocatalysis under visible light. Because conjugated polyHIPEs act as photocatalysts having a stable inherent porous skeleton, the use of additional support materials such as silica gels ${ }^{14}$ and zeolites ${ }^{15}$ can be eliminated. Classical polyHIPEs have rather low surface areas (up to $50 \mathrm{~m}^{2} \mathrm{~g}^{-1}$ ). ${ }^{16,17}$ It was later shown that the surface area of polyHIPEs can be tuned by varying the cross-linker content or by hypercrosslinking the system via chemical functionalization. ${ }^{18-21}$ Nonetheless, these methods are not suitable for conjugated

Max Planck Institute for Polymer Research, Ackermannweg 10, D-55128 Mainz, Germany.E-mail: kai.zhang@mpip-mainz.mpg.de

$\dagger$ Electronic supplementary information (ESI) available: Monomer synthesis, FT-IR and fluorescence spectra, TGA, ${ }^{1} \mathrm{H},{ }^{13} \mathrm{C}$ and solid state ${ }^{13} \mathrm{C} \mathrm{CP} / \mathrm{MAS}$ NMR spectra, $\mathrm{N}_{2}$ sorption isotherms and pore size distribution, theoretical calculations and additional SEM and TEM Images. See DOI: 10.1039/c4cc02861a
polyHIPEs to be used as photocatalysts since the chemical composition of the conjugated polyHIPEs is of vital importance to their photochemical properties and photocatalytic performance.

Organic sulfides are key intermediates in pharmaceutical or other fine chemical industries. ${ }^{22,23}$ Selective oxidation of sulfides to the corresponding sulfoxides is traditionally achieved using stoichiometric amounts of organic or inorganic oxidants, which usually generates huge amounts of toxic byproducts or heavy metal wastes. $^{24,25}$ Recent developments in catalysts based on organometallic complexes have been attempted to alleviate this problem but they still generally require substantial amounts of additional oxidants, such as $\mathrm{H}_{2} \mathrm{O}_{2}$ at elevated temperatures, ${ }^{26,27}$ urea hydroperoxide, ${ }^{28}$ and isobutyraldehyde. ${ }^{29}$ Thus, conjugated polyHIPEs have the clear advantage of serving as green, effective, chemoselective and recyclable photocatalysts that require only visible light and air. Not only can the conjugated polyHIPEs be easily removed and recycled after use, they can also be readily incorporated into continuous flow systems, which offer facile automation, precise control over reaction parameters and a predictable scale-up. ${ }^{13}$

Herein, we report on the design and preparation of high surface area conjugated porous polymers via high internal phase emulsion polymerization and micropore surface engineering. By incorporation and removal of the cleavable tert-butyl carboxylate (Boc) functional group as a spacer into the polymer network, the surface area can be increased up to eight times, gaining extra porosity. The photocatalytic activity of the polymers for highly selective oxidation of organic sulfides to the desired mono-oxidized sulfoxides under visible light irradiation was also described. Furthermore, the influence of the surface area and energetic level on the photocatalytic performance was investigated by introducing a wellstudied electron acceptor, the benzothiadiazole (BT) unit into the polymer backbone.

The porous polymers were synthesized via the Suzuki-Miyaura cross-coupling reaction (Scheme 1). The detailed synthetic pathway and the characterization of the monomers and polymers are described in the ESI. $\dagger$ The thermogravimetric analysis (TGA) of the Boc containing polymers showed a significant weight loss at $250{ }^{\circ} \mathrm{C}$ under $\mathrm{N}_{2}$, indicating the thermal cleavage of the Boc group 


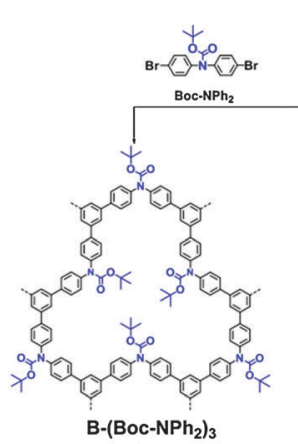

(ii)

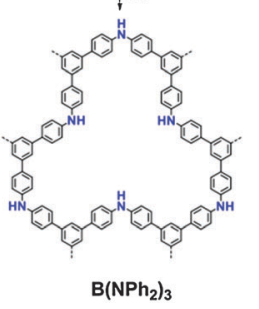

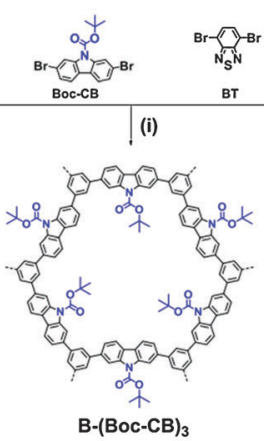

(ii)

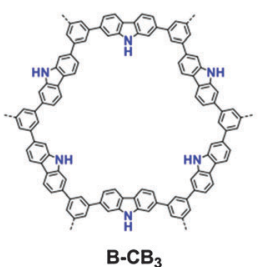

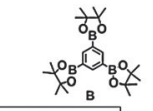

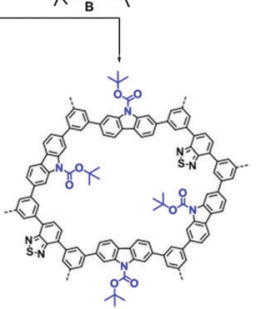

B-(Boc-CB) $)_{2}$-BT

(ii)

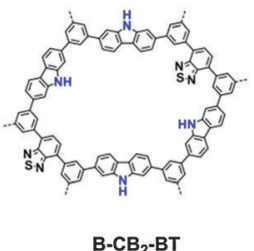

Scheme 1 Idealized structures and surface area control via micropore engineering of conjugated porous polymers. Reaction conditions: (i) $\mathrm{Pd}\left(\mathrm{PPh}_{3}\right)_{4}$, span 80 , toluene $/ \mathrm{H}_{2} \mathrm{O}(1 / 9), 80^{\circ} \mathrm{C}$, overnight. (ii) $250{ }^{\circ} \mathrm{C}, 12 \mathrm{~h}$ under vacuum.

inside the porous polymers (Fig. S12 in the ESI $\dagger$ ). The FTIR spectra confirmed the disappearance of the typical signals for $=\mathrm{C}=\mathrm{O}$ groups at $1750 \mathrm{~cm}^{-1}$ (Fig. $\mathrm{S} 7-\mathrm{S} 9$, ESI $\dagger$ ). The solid-state ${ }^{13} \mathrm{C} / \mathrm{MAS}$ NMR showed a significant decrease of chemical shifts at $\delta=30$ and 80 and $155 \mathrm{ppm}$, which are assigned to the $-\mathrm{CH}_{3}$, quart. $\mathrm{C}$ and $=\mathrm{C}=\mathrm{O}$ groups of the Boc moiety. The signals between 100 and $160 \mathrm{ppm}$, which are assigned to the aromatic rings in the polymer backbones, remained unchanged (Fig. S14-S19, ESI $\dagger$ ). This indicates that upon the thermal treatment the aromatic structure stays intact.

The Brunauer-Emmett-Teller (BET) surface areas of all three polymers increased significantly after the thermal removal of the Boc group. In particular, surface areas ranged from $198 \mathrm{~m}^{2} \mathrm{~g}^{-1}$ for $\mathrm{B}-\left(\mathrm{NPh}_{2}\right)_{3}$ to $230 \mathrm{~m}^{2} \mathrm{~g}^{-1}$ for $\mathrm{B}^{-\mathrm{CB}_{3}}$ and $53 \mathrm{~m}^{2} \mathrm{~g}^{-1}$ for $\mathrm{B}-\mathrm{CB}_{2}-\mathrm{BT}$, exhibiting an increasing factor of 4,8 and 2 times from $\mathrm{B}-(\mathrm{Boc}-$ $\left.\mathrm{NPh}_{2}\right)_{3}$ with $45 \mathrm{~m}^{2} \mathrm{~g}^{-1}$, B-(Boc-CB) $)_{3}$ with $27 \mathrm{~m}^{2} \mathrm{~g}^{-1}$, and B-(Boc-CB)BT with $26 \mathrm{~m}^{2} \mathrm{~g}^{-1}$, respectively (Fig. S20 and S21, ESI $\dagger$ ). Likewise, the total pore volumes of the porous polymers also increased, and the micropore diameter was $c a$. $1.5 \mathrm{~nm}$, estimated via this micropore modification method. The data are listed in Table S1 of the ESI. $\dagger$

In Fig. 1, SEM images of the two series of polyHIPEs are displayed. The polyHIPE series after the Boc cleavage appeared to have a very similar morphology as that of the series containing Boc, showing interconnected pore structures. The cavities of the polyHIPEs ranged from $10 \mu \mathrm{m}$ to $20 \mu \mathrm{m}$ in size whereas the interconnected pores have diameters of about $1 \mu \mathrm{m}$. To note is that the removal of the Boc group upon heat treatment did not affect the stability of the macrostructure and the porous skeleton remained intact. A significant number of micropores $(d=\sim 1.5 \mathrm{~nm})$ appeared according to the pore size distribution measurement after the Boc cleavage.

The UV/Vis diffuse reflectance spectra (DRS) of the polymers were slightly bathochromically shifted after the removal of the

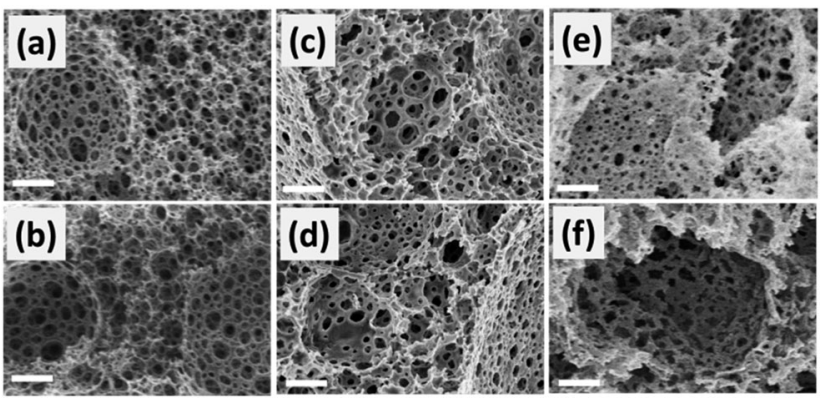

Fig. 1 SEM image of the conjugated polyHIPEs before and after the removal of the Boc group. (a) B-(Boc-NPh $)_{3}$, (b) B- $\left(\mathrm{NPh}_{2}\right)_{3}$, (c) B-(Boc-CB $)_{3}$, (d) B-CB, (e) B-(Boc-CB) $2-B T$, and (f) B-CB $-B T$. Scale bar: $2 \mu \mathrm{m}$.

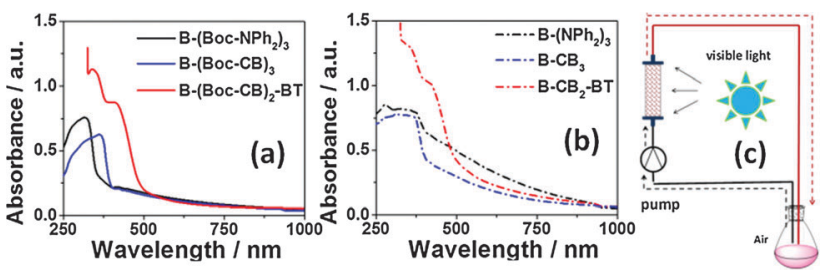

Fig. 2 (a) UV/Vis DR spectra of B-(Boc-NPh $)_{3}, \mathrm{~B}-(\mathrm{Boc}-\mathrm{CB})_{3}$, and B-(Boc$\mathrm{CB})_{2}$-BT containing Boc groups. (b) UV/Vis DR spectra of $\mathrm{B}-\left(\mathrm{NPh}_{2}\right)_{3}, \mathrm{~B}-\mathrm{CB}_{3}$, and $B-(C B)_{2}-B T$. (c) An illustrated setup of the glass column photoreactor in a continuous flow system, the porous polymers are inserted into the gas column.

Boc moiety (Fig. 2b), compared to the ones containing Boc (Fig. 2a). This shift could be caused by the thermal annealing effect of the conjugated polymer backbone, leading to more ordered $\pi-\pi$-stacking, and therefore slightly lower energy levels.

By introducing the strong electron acceptor BT unit into the polymer backbone, a bathochromic shift of $c a .55 \mathrm{~nm}$ occurred, indicating lower HOMO and LUMO levels and narrower band gaps. Similarly, the photoluminescence (PL) spectra of B-(Boc-CB) $)_{2}^{-}$ $\mathrm{BT}$ and $\mathrm{B}-\mathrm{CB}_{2}-\mathrm{BT}$ are largely bathochromically shifted compared to B-(Boc-CB $)_{3}$ and $\mathrm{B}-\mathrm{CB}_{3}$ (Fig. S10 and S11 in the $\mathrm{ESI} \dagger$ ). An extra fluorescence band at about $520 \mathrm{~nm}$ occurred for both BT containing polymers. This large Stokes shift reflects a stronger $\pi-\pi^{*}$-transition of the electrons under excitation. The $\mathrm{NPh}$-based polymers B-(Boc-NPh$)_{3}$ and B- $\left(\mathrm{NPh}_{2}\right)_{3}$ exhibited the largest optical HOMO-LUMO band gaps of 3.31 and $3.03 \mathrm{eV}$, followed by the B-(Boc-CB) $)_{3}$ with 3.02 and $\mathrm{B}-\mathrm{CB}_{3}$ with $2.83 \mathrm{eV}$. The lowest bad gaps were exhibited by B-(Boc-CB $)_{2}$-BT with 2.47 and $\mathrm{B}-\mathrm{CB}_{2}$-BT with 2.31 (Table 1 ).

To investigate the electronic properties, theoretical HOMOLUMO levels of the repeating units were calculated. The data are listed in Table S3 and the electronic structures are displayed in Fig. S24 and S25 in the ESI. $\dagger$ Similar to the optical band gaps, the NPh-containing units exhibited the highest HOMO-LUMO gap, followed by the CB-based ones. And the BT-containing units showed clearly lower band gaps. In contrast, all repeating units exhibited similar HOMO levels ranging from -5.40 to $-5.90 \mathrm{eV}$. However, the LUMO levels of the BT-containing $\mathrm{B}-\left(\mathrm{Boc}-\mathrm{CB}_{2}\right)$-BT and $\mathrm{B}-\mathrm{CB}_{2}-\mathrm{BT}$ of $c a$. $-3.10 \mathrm{eV}$ were significantly lower than the NPh- and CB-based polymers $(-1.10$ to $-1.60 \mathrm{eV})$. A better electron transition can be expected. 
Table 1 Photocatalytic oxidation of thioanisole using conjugated polyHIPEs as heterogeneous photocatalysts under visible light: (a) thioanisole, (b) methyl phenyl sulfoxide and (c) methyl phenyl sulfone, and the optical and electronic properties

\begin{tabular}{|c|c|c|c|c|c|c|}
\hline \multirow[b]{3}{*}{ Entry } & \multicolumn{2}{|c|}{$\begin{array}{l}\underset{\text { polyHIIPEs }}{\text { air, acetonitrile }} \\
\mathrm{RT}, h v(460 \mathrm{~nm})\end{array}$} & \multirow[t]{2}{*}{ b } & & c & \multirow{3}{*}{$\begin{array}{l}\text { Band } \\
\text { gap/opt } \\
(\mathrm{eV})\end{array}$} \\
\hline & \multirow[b]{2}{*}{ PolyHIPEs } & \multirow[b]{2}{*}{$t /(\mathrm{h})$} & & \multicolumn{2}{|c|}{ Selectivity (\%) } & \\
\hline & & & $\begin{array}{l}\text { Conv. } \\
(\%)\end{array}$ & $b$ & $c$ & \\
\hline 1 & B- $\left(\text { Boc-NPh }{ }_{2}\right)_{3}$ & 48 & 38 & $>99$ & $<1$ & 3.31 \\
\hline 2 & $\mathrm{~B}-\left(\mathrm{NPh}_{2}\right)_{3}$ & 48 & 33 & $>99$ & $<1$ & 3.03 \\
\hline 3 & B- $(\text { Boc-CB })_{3}$ & 48 & 91 & $>99$ & $<1$ & 3.02 \\
\hline 4 & $\mathrm{~B}-\mathrm{CB}_{3}$ & 48 & 93 & $>99$ & $<1$ & 2.83 \\
\hline 5 & $\mathrm{~B}-(\mathrm{Boc}-\mathrm{CB})_{2}-\mathrm{BT}$ & 24 & 99 & 95 & 5 & 2.47 \\
\hline 6 & $\mathrm{~B}-\mathrm{CB}_{2}-\mathrm{BT}$ & 24 & 98 & 99 & $<1$ & 2.31 \\
\hline Blank $^{a}$ & - & 24 & - & - & - & - \\
\hline Blank $^{b}$ & $\mathrm{~B}-(\mathrm{Boc}-\mathrm{CB})_{2}-\mathrm{BT}$ & 24 & - & - & - & - \\
\hline
\end{tabular}

${ }^{a}$ No polymer, but under light irradiation. ${ }^{b}$ Using B-(Boc-CB) $)_{2}-\mathrm{BT}$ as a photocatalyst, but no light irradiation. General reaction conditions: $10 \mathrm{mg}$

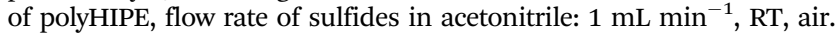

The photocatalytic activity of the conjugated porous polymers as heterogeneous photocatalysts under visible light was investigated by the photooxidation of thioanisole at room temperature in a continuous flow system as displayed in Fig. 2c. As shown in Table 1, an almost quantitative selectivity ( $>99 \%$ ) of the photooxidation of thioanisole to the desired mono-oxidized product methyl phenyl sulfoxide was obtained. PolyHIPEs containing the CB moiety showed higher conversions than those with $\mathrm{NPh}_{2}$ moieties, and the polymers containing a strong electron acceptor, BT unit, exhibited the best photocatalytic efficiency. This corresponds with the lower HOMO-LUMO band gaps, in particular, the low LUMO levels according to the theoretical calculation.

To note, the series of the polyHIPEs without the Boc moieties, $\mathrm{B}-\left(\mathrm{NPh}_{2}\right)_{3}, \mathrm{~B}-\mathrm{CB}_{3}$, and $\mathrm{B}-\mathrm{CB}_{2}-\mathrm{BT}$, with higher BET surface areas did not distinguish themselves as more efficient photocatalysts than their counterparts with Boc. This can be attributed to the micropores, which after the removal of the Boc moieties were still too small $(d=1.5 \mathrm{~nm})$ to allow efficient mass diffusion of the reactants. This finding further proves that in heterogeneous catalysis, it rather depends on the larger pores $(>1 \mu \mathrm{m})$ that play a more vital role in providing accessible surface sites for interfacial reactions than the micropores $(<2 \mathrm{~nm}) \cdot{ }^{30-32} \mathrm{~B}-(\mathrm{Boc}-\mathrm{CB})_{2}-\mathrm{BT}$ and $\mathrm{B}_{-} \mathrm{CB}_{2}-\mathrm{BT}$ exhibited almost quantitative conversions within $24 \mathrm{~h}$ in acetonitrile (entries 5 and 6 in Table 1) with 95\% and 99\% selectivity, respectively. Likely, the reaction time $(24 \mathrm{~h})$ might be too long for B-(Boc-CB) $)_{2}-\mathrm{BT}$ as an active photocatalyst, and an overoxidation of $5 \%$ occurred.

The photocatalytic experiment suggests that the $\pi$-electrons in the conjugated polymer backbone play a more crucial role in the photocatalytic feasibility than the surface area. This further proved a previous study on a series of conjugated porous polymers as photosensitizers, which showed that the polymers containing strong electron acceptor units such as BT could generate singlet oxygen in a more efficient manner. ${ }^{13}$ And most importantly, low LUMO levels are mandatory.
Five additional repeat experiments were carried out for investigating the photooxidation of thioanisole using B-(Boc-CB) $)_{2}-\mathrm{BT}$ under the same reaction conditions (Table S2 in the ESI $\dagger$ ). The desired mono-oxidised product was obtained in an almost quantitative manner, demonstrating the stability and reusability of the polyHIPE. The oxidation of sulfides is likely mediated by photochemically generated singlet oxygen, which should be similar to a previous study. ${ }^{33}$ Blank experiments were also carried out as a control (Table 1). The same reaction was tested by using the polyHIPE as the photocatalyst, but without light irradiation; or without the polyHIPE, but under light irradiation. No oxidized product was obtained in both experiments, indicating that both components are indispensable.

For the determination of the general applicability of the selective photooxidation of organic sulfides, a number of various thioanisole derivatives were examined under the same reaction conditions. $\mathrm{B}-(\mathrm{Boc}-\mathrm{CB})_{2}$-BT was used in all reactions due to its high photocatalytic activity. The data are listed in Table 2 . We tested different phenyl sulfides bearing electron-withdrawing (entries 7-9) or electron-donating substituents (entries 10 and 11) on the phenyl ring as substrates for the oxidation reaction. All reactions exhibited high selectivity of the mono-oxidated sulfoxides. The conversion corresponded to the electron-withdrawing ability of the substituents $(-\mathrm{Cl}<-\mathrm{Br}<-\mathrm{F})$. In case of the electron-donating substituents (entry 10 and 11), the conversion followed the opposite order of the electron affinity $\left(-\mathrm{CH}_{3}<-\mathrm{OCH}_{3}\right)$. Allyl phenyl sulfide with a considerable selectivity of $88 \%$ (entry 12) and ethyl phenyl sulfide (entry 13 ) with $>99 \%$ were employed to demonstrate the chemoselectivity of the photooxidation reaction.

In conclusion, we reported a novel method to synthesize high surface area conjugated porous polymers with unique electronic properties via high internal phase emulsion polymerization and

Table 2 Selective oxidation of various sulfides using B-(Boc-CB) $2-B T$ as a photocatalyst under visible light irradiation ${ }^{a}$

Conv. (\%)

${ }^{a}$ Reaction conditions: $10 \mathrm{mg}$ of B-(Boc-CB) $)_{2}$-BT, flow rate of sulfides in

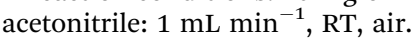


micropore surface engineering. The tert-butyl carboxylate (Boc) group was introduced as a spacer into the micropores of the cross-linked polymer networks. The BET surface of the porous polymers can be increased by a factor of eight in the best cases. They exhibit porosity with the pore size ranging from micrometers to nanometers. The photocatalytic activity of the conjugated porous polymers was demonstrated via photooxidation of organic sulfides to sulfoxides under visible light, achieving an almost quantitative conversion and selectivity in the best cases. It is worth noting that high surface areas did not play a crucial role with respect to the photocatalytic efficiency. Nanometer sized pores of $c a .1 .5 \mathrm{~nm}$ are indeed insufficient for reactants to diffuse in. The more important factor was the electronic structure, i.e. the donor and acceptor combination of the polymer backbone, with the best photocatalytic activity being shown by the polymer containing the benzothiadiazole unit as a strong acceptor. This is in consonance with the lower optical HOMO-LUMO band gap values of the BT containing polymers resulting from the significantly low LUMO levels of the polymers. Nevertheless, conjugated porous polyHIPEs still offer a new class of stable visible lightdriven heterogeneous catalytic systems. By incorporation of the insoluble polymers into a glass column reactor, the product can be obtained continuously without separation from the catalysts.

The Max Planck Society is acknowledged for financial support.

\section{Notes and references}

1 L. Chen, Y. Honsho, S. Seki and D. Jiang, J. Am. Chem. Soc., 2010, 132, 6742-6748.

2 A. I. Cooper, Adv. Mater., 2009, 21, 1291-1295.

3 Y. Chen, J. Zhang, M. Zhang and X. Wang, Chem. Sci., 2013, 4, 3244-3248.

4 X. C. Wang, K. Maeda, A. Thomas, K. Takanabe, G. Xin, J. M. Carlsson, K. Domen and M. Antonietti, Nat. Mater., 2009, 8, 76.

5 F. Vilela, K. Zhang and M. Antonietti, Energy Environ. Sci., 2012, 5, 7819-7832.

6 M. Bokhari, R. J. Carnachan, N. R. Cameron and S. A. Przyborski, Biochem. Biophys. Res. Commun., 2007, 354, 1095-1100.

7 N. Dizge, B. Keskinler and A. Tanriseven, Colloids Surf., B, 2008, 66, 34-38.
8 S. J. Pierre, J. C. Thies, A. Dureault, N. R. Cameron, J. C. M. van Hest, N. Carette, T. Michon and R. Weberskirch, Adv. Mater., 2006, 18, 1822-1826.

9 F. Su, C. L. Bray, B. Tan and A. I. Cooper, Adv. Mater., 2008, 20, 2663-2666.

10 E. H. Mert, H. Yıldırım, A. T. Üzümcü and H. Kavas, React. Funct. Polym., 2013, 73, 175-181.

11 M. Ottens, G. Leene, A. A. C. M. Beenackers, N. Cameron and D. C. Sherrington, Ind. Eng. Chem. Res., 2000, 39, 259-266.

12 W. L. Li, W. J. Zhang, X. Q. Dong, L. S. Yan, R. G. Qi, W. C. Wang, Z. G. Xie and X. B. Jing, J. Mater. Chem., 2012, 22, 17445-17448.

13 K. Zhang, Z. Vobecka, K. Tauer, M. Antonietti and F. Vilela, Chem. Commun., 2013, 49, 11158-11160.

14 P. Saint-Cricq, T. Pigot, L. Nicole, C. Sanchez and S. Lacombe, Chem. Commun., 2009, 5281-5283.

15 A. Sanjuan, G. Aguirre, M. Alvaro and H. Garcia, Appl. Catal., B, 1998, 15, 247-257.

16 I. Pulko and P. Krajnc, Macromol. Rapid Commun., 2012, 33, 1731-1746.

17 S. D. Kimmins and N. R. Cameron, Adv. Funct. Mater., 2011, 21, 211-225.

18 A. Barbetta, M. Dentini, L. Leandri, G. Ferraris, A. Coletta and M. Bernabei, React. Funct. Polym., 2009, 69, 724-736.

19 M. G. Schwab, I. Senkovska, M. Rose, N. Klein, M. Koch, J. Pahnke, G. Jonschker, B. Schmitz, M. Hirscher and S. Kaskel, Soft Matter, 2009, 5, 1055-1059.

20 I. Pulko, J. Wall, P. Krajnc and N. R. Cameron, Chem. - Eur. J., 2010, 16, 2350-2354.

21 U. Sevšek, J. Brus, K. Jeřabek and P. Krajnc, Polymer, 2014, 55, 410-415.

22 A. Padwa, W. H. Bullock and A. D. Dyszlewski, J. Org. Chem., 1990, 55, 955-964.

23 I. Fernandez and N. Khiar, Chem. Rev., 2003, 103, 3651-3705.

24 J.-E. Bäckvall, Modern oxidation methods, Wiley-VCH, Weinheim, Germany, 2nd edn 2010.

25 K. Kaczorowska, Z. Kolarska, K. Mitka and P. Kowalski, Tetrahedron, 2005, 61, 8315-8327.

26 J. Perles, M. Iglesias, C. Ruiz-Valero and N. Snejko, J. Mater. Chem., 2004, 14, 2683-2689.

27 J. Perles, M. Iglesias, M. A. Martin-Luengo, M. A. Monge, C. RuizValero and N. Snejko, Chem. Mater., 2005, 17, 5837-5842.

28 D. N. Dybtsev, A. L. Nuzhdin, H. Chun, K. P. Bryliakov, E. P. Talsi, V. P. Fedin and K. Kim, Angew. Chem., Int. Ed., 2006, 45, 916-920.

29 L. Chen, Y. Yang and D. L. Jiang, J. Am. Chem. Soc., 2010, 132, 9138-9143.

30 F. Z. Su, S. C. Mathew, G. Lipner, X. Z. Fu, M. Antonietti, S. Blechert and X. C. Wang, J. Am. Chem. Soc., 2010, 132, 16299-16301.

31 X. C. Wang, K. Maeda, X. F. Chen, K. Takanabe, K. Domen, Y. D. Hou, X. Z. Fu and M. Antonietti, J. Am. Chem. Soc., 2009, 131, 1680-1681.

32 Y. Chen, J. S. Zhang, M. W. Zhang and X. C. Wang, Chem. Sci., 2013, 4, 3244-3248.

33 K. Zhang, D. Kopetzki, P. H. Seeberger, M. Antonietti and F. Vilela, Angew. Chem., Int. Ed., 2013, 52, 1432-1436. 